\title{
Haemorrhage Involving the Central Nervous System in Haemophilia : Account of the Management of Five Cases
}

\author{
B. M. FESSEY,* M.B., B.S. ; M. J. MEYNELL,* M.D., B.SC., D.P.H., F.R.C.P.
}

Brit. med. F., 1966, 2, 211-212

A leading article in the British Medical fournal (1964) emphasized the poor prognosis for survival when haemorrhage involves the central nervous system in haemophilia. The purpose of this communication is to describe our experience with five such cases, only one of which terminated fatally, a result due largely to treatment with antihaemophilic globulin (A.H.G.). concentrates which have been available since 1958.

Since 1954, at this hospital, a register has been kept of haemophiliacs and patients with allied disorders residing in the West Midland area. Up to date we have had 191 haemophiliacs (A.H.G. (factor VIII) deficiency), 20 patients with Christmas disease (plasma thromboplastin component (P.T.C., factor IX) deficiency), and 15 with von Willebrand's disease (capillary defect with or without A.H.G. deficiency). These were diagnosed by the thromboplastin generation test (Biggs and Douglas, 1953). The normal range of A.H.G. by the method used (Biggs, Eveling, and Richards, 1955) was $50 \%$ to $150 \%$.

During this period 306 patients over the age of 14 were admitted, with three deaths. The first, that of a man of 60 , occurred from ascending pyelonephritis and uraemia following prostatectomy. The second, that of a severe haemophiliac of 45 , was also from pyelonephritis and uraemia after local removal by diathermy of a malignant papilloma of the bladder. The third patient, a severe haemophiliac of 20 , had a spontaneous acute subdural haemorrhage.

Of the 306 admissions, five (including the patient already mentioned) had haemorrhage involving the central nervous system ; four were haemophiliacs and the fifth had Christmas disease. Trauma followed by progressive increase in neurological signs presents no diagnostic problem. In the absence of a history of injury we consider that headache lasting more than 12 hours is an indication for replacement therapy. We have avoided the use of routine diagnostic procedures available to patients without coagulation defects-for example, lumbar puncture, carotid angiography, and craniotomy-since we believe that any of these are capable of producing fatal haemorrhage.

\section{Case 1}

An iron-foundry worker aged 21, a mild haemophiliac (A.H.G., $4 \%$ ) was admitted to this hospital on 4 May 1962 . He had suffered little disability apart from epistaxis and prolonged haemorrhage after dental extractions. Ten days before admission he complained of headache, which became progressively worse, and within a few hours he collapsed and was unconscious for about three minutes. On recovery he vomited several times. The headache persisted, so he was admitted to hospital and then transferred to a neurosurgical unit with the diagnosis of subarachnoid haemorrhage. Because of the haemophilia he was sent to us.

On examination he was drowsy and had slurred speech, difficulty in swallowing, neck stiffness, photophobia, bilateral sixth-nerve paralysis (complete on the left side and partial on the right), left homonymous hemianopia, and facial weakness on that side.

No investigations were undertaken to confirm the diagnosis, and replacement therapy was begun immediately- $500 \mathrm{ml}$. of fresh frozen plasma six-hourly for two days. Though there was no

* Department of Clinical Pathology, the General Hospital, Birmingham. further deterioration, improvement was not striking, and on the third day intravenous therapy was supplemented with human A.H.G. concentrate, obtained from the Lister Institute. Two bottles of this (equivalent to $900 \mathrm{ml}$. of fresh plasma) plus $500 \mathrm{ml}$. of fresh frozen plasma were given daily for the next five days. Improvement was rapid. He became increasingly alert and asked to see his wife and child. Fresh frozen plasma, $500 \mathrm{ml}$. daily, was given for a further 12 days. He was discharged to a convalescent home. One month later all that was found was a slight paresis of the left sixth nerve. Three months later this was barely detectable.

Comment.-Though the response with fresh frozen plasma alone was not striking, dramatic improvement followed the addition of human A.H.G. concentrate.

\section{Case 2}

A boy aged 13, a severe haemophiliac (A.H.G. 0\%), had had repeated haemarthroses, with occasional intra-abdominal bleeding and epistaxes. He was admitted on 17 October 1961 complaining of headache, and was given $500 \mathrm{ml}$. of fresh frozen plasma daily for two days, though neurological examination showed no abnormality. The headache then disappeared and he was discharged home.

Three weeks later he was readmitted with a recurrence of the headache. There was some aphasia. He was given $1,000 \mathrm{ml}$. of fresh frozen plasma over the next two days. On the third day he appeared drowsy and had a generalized fit. A further 1,000 ml. of fresh frozen plasma was given and he was transferred to the Churchill Hospital, Oxford, under the care of Dr. P. C. Mallam. On admission he was drowsy and the left fundus showed early papilloedema. He was given human A.H.G. concentrate daily for four days and rapidly improved. When discharged on 23 December all signs and symptoms had disappeared.

Comment.-A case of spontaneous cerebrovascular accident leading to left frontoparietal cerebral compression with complete recovery after treatment with human A.H.G. concentrate and fresh frozen plasma. As in the previous case, the diagnosis was presumptive.

\section{Case 3}

A boy aged 13, a mild case of Christmas disease (clotting-time 7 minutes), had had very little trouble apart from easy bruising. He was admitted on 19 May 1964, having fallen from a tree on to his head, with momentary loss of consciousness. Examination showed no abnormal neurological signs. Laceration of the scalp and swelling of the face rapidly subsided after the administration of $500 \mathrm{ml}$. of fresh frozen plasma daily for three days. On the fifth day he suddenly developed a complete quadriplegia with intense pain over the neck and shoulders. Examination revealed a positive Kernig's sign, neck-stiffness, complete paralysis of the legs, and weakness of the arms. There was a loss of pain and touch sensation over the upper chest, inner aspects of the arms and forearms, the whole of the abdomen, and the legs. $X$-ray examination of the spine showed no fracture. A presumptive diagnosis of extradural haemorrhage in the region of C6 was made. He was given $500 \mathrm{ml}$ of fresh frozen plasma and Christmas factor concentrate over the next two hours. Improvement was rapid, and for the next week he was given $500 \mathrm{ml}$. of fresh frozen plasma daily. He was discharged one week later, having fully recovered. 
Comment.-Compression of the lower cervical cord by haemorrhage following trauma rapidly subsided on treatment with fresh frozen plasma and Christmas factor concentrate.

\section{Case 4}

A shop assistant aged 20, a severe haemophiliac (A.H.G. 0\%), had attended a special school for the physically handicapped as a child. He had had repeated haemarthroses, epistaxes, and intraabdominal bleeding.

He was admitted on 15 August 1964 complaining of having had headache and vomiting for 10 days. There was no abnormality apart from drowsiness and no papilloedema. He had been taking methadone hydrochloride in a larger dosage than that prescribed by his doctor, and this was thought to have caused the drowsiness.

$\mathrm{He}$ was given $500 \mathrm{ml}$. of fresh frozen plasma, and the next day he was much better.

His behaviour after his mother's death some months previously had been regarded as odd by his relatives. During this time he was admitted to various hospitals for pain in the chest and arms. Recovery was complete on each occasion without specific therapy.

Investigations, including a full blood count, E.S.R., and $x$-ray examination of the skull, showed nothing abnormal. Because of the history and the absence of physical signs, treatment with fresh frozen plasma was stopped after the third day. He remained in hospital for observation and psychiatric opinion. Mild headache persisted, pulse and temperature were normal. A complete neurological examination was made daily. On the fourth day early papilloedema of the left fundus, slurred speech, and a right sixth nerve palsy were found. Abdominal reflexes were absent and both plantars were extensor. Fresh frozen plasma was given immediately $-500 \mathrm{ml}$. in one hour, repeated three-hourly. Nine hours later, because of increasing drowsiness, he was given 1,000 units of porcine A.H.G. and then 400 units four-hourly, but he lapsed into coma and died early the next morning. Post-mortem examination revealed an extensive subdural haemorrhage over both cerebral hemispheres but no other abnormalities.

Comment.-The error in this case was the inability to appreciate the significance of the headache. Too much emphasis was placed on his mental state before the last admission. Craniotomy might have been successful as late as the evening before death.

\section{Case 5}

A works inspector aged 34, a severe haemophiliac (A.H.G. 30\%) was transferred to this hospital on 28 August 1964 in a comatose state after a motor-cycle accident. He had been admitted to a peripheral hospital immediately after the accident without evidence of central nervous system involvement. He had repeated haemarthroses in the past, with epistaxes and occasional haematuria.

Facial lacerations and a large haematoma were present over the left zygoma ; $x$-ray examination confirmed a depressed fracture. There was areflexia of all limbs, pupils were equal and reacted sluggishly to light, fundi did not show papilloedema. Pulse rate was $60 /$ minute and he responded to painful stimuli. A presumptive diagnosis of cerebral injury with haemorrhage was made.

Treatment was started with bovine A.H.G. 1,000 units stat. and 1,000 units six-hourly for nine days, then reduced to 500 units six-hourly for a further period of 14 days. Altogether he received 65,000 units of bovine A.H.G. Intravenous hydrocortisone, 200 mg. daily in divided doses, was given from the eighth day because of the obvious reaction to foreign protein-that is, rash, pyrexia. By the third week he showed some improvement and the bovine A.H.G. concentrate was discontinued. Fresh frozen plasma, 2-4 l. daily for a further week, definitely improved his mental state.

$\mathrm{He}$ was discharged home on 29 September, a month after admission, and when seen two months later as an outpatient neurological signs were minimal. There was slight paresis of the right arm and leg, but as the joints were ankylosed it was difficult to assess the neurological disability. His wife said his mental state had not changed as a result of the accident.

Comment.-Large dosage with bovine A.H.G. over 23 days resulted in an almost complete recovery, after he had been unconscious for two and a half weeks. It is of interest that his brother, a haemophiliac also, had had a motor-cycle accident four years previously, which resulted in a ruptured liver. He eventually recovered after treatment with bovine A.H.G.

\section{Discussion}

In four of the five cases described the diagnosis of haemorrhage involving the central nervous system was not confirmed, although all showed progressive neurological involvement. The response to replacement therapy with concentrates was dramatic and complete in four. In two the incident followed trauma. In the third an extensive subdural haematoma was seen at postmortem examination. The remaining two patients had intense headache with loss of consciousness, which improved slowly with relatively inadequate plasma replacement, but subsequently resolved completely with A.H.G. concentrate of human or animal origin. The advantage of concentrates over fresh plasma apart from their greater potency is that the circulating blood volume is not raised to the same extent, thus minimizing the likelihood of inducing further haemorrhage. The one failure was due to inability to assess the symptoms and signs owing to the previous history of abnormal behaviour.

Headache lasting for more than 12 hours in a haemophiliac is an indication for immediate and adequate replacement therapy. Aggeler and Lucia (1944) recommend $250 \mathrm{ml}$. of fresh frozen plasma two-hourly for 10 hours and then $500 \mathrm{ml}$. eight-hourly as long as signs or symptoms persist. The response is usually rapid, and can be used as a diagnostic test. Within 8 to 10 hours of starting treatment a definite improvement is noted.

Lumbar puncture was not performed on any of the patients described, although Silverstein (1960) has done 29 punctures on six patients with only rare external bleeding. He recommends a plasma transfusion of $250 \mathrm{ml}$. immediately before the procedure.

Once the patient has improved there is no justification for any other diagnostic or therapeutic surgical procedure. Craniotomy should be performed only as a last resort. The haemorrhage following this can result in death of the patient despite the relief of raised intracranial pressure. Carotid angiography is too dangerous a procedure in these cases.

\section{Summary}

A report of the management of five cases of haemophilia with haemorrhage involving the central nervous system is given. Four of these made a good recovery; one died.

The conservative diagnostic approach is emphasized, avoiding the routine procedures available to patients with no coagulation defects.

Treatment was with infusions of fresh plasma and A.H.G. and Christmas factor concentrates. Although deterioration in the clinical condition was halted with fresh plasma, recovery rapidly followed the use of concentrates. These have the added advantages of greater potency and less bulk, both of importance in preventing further haemorrhage. This treatment on the whole compares favourably with previous reports of treatment in this condition (Silverstein, 1960 ; Kerr, 1964).

We wish to thank the Endowment Research Fund of the United Birmingham Hospitals for financial assistance; Dr. W. Maycock, of the Lister Institute, for supplies of human A.H.G. concentrate ; and Dr. Rosemary Biggs and Professor R. G. Macfarlane, of the Medical Research Council Blood Coagulation Research Unit, Oxford, for their advice and supply of Christmas factor concentrate.

\section{REFERENCES}

Aggeler, P. M., and Lucia, S. P. (1944). 7. nerv. ment. Dis., 99, 475. Aggeler, P. M., Douglas, A. S. (1953). f. clin. Path., 6, 23. Biggs, R., Hat. H. Haemat., 1, 20. Brit. med. F. 1964, 2, 1089.

Brit. med. F., 1964, 2, Neurol. Neurosurg. Psychiat., 27, 166.

Silverstein, A. (1960). Arch. Neurol. (Chic.), 3, 141. 